Hydrol. Earth Syst. Sci., 17, 3295-3303, 2013

www.hydrol-earth-syst-sci.net/17/3295/2013/

doi:10.5194/hess-17-3295-2013

(C) Author(s) 2013. CC Attribution 3.0 License.

\title{
Socio-hydrology: conceptualising human-flood interactions
}

\author{
G. Di Baldassarre ${ }^{1}$, A. Viglione ${ }^{2}$, G. Carr ${ }^{3}$, L. Kuil ${ }^{3}$, J. L. Salinas ${ }^{2}$, and G. Blöschl' ${ }^{2,3}$ \\ ${ }^{1}$ Department of Integrated Water Systems and Governance, UNESCO-IHE, Delft, the Netherlands \\ ${ }^{2}$ Institute of Hydraulic Engineering and Water Resources Management, Vienna University of Technology, Vienna, Austria \\ ${ }^{3}$ Centre for Water Resource Systems, Vienna University of Technology, Vienna, Austria
}

Correspondence to: G. Di Baldassarre (g.dibaldassarre@unesco-ihe.org) and A. Viglione (viglione@hydro.tuwien.ac.at)

Received: 22 March 2013 - Published in Hydrol. Earth Syst. Sci. Discuss.: 9 April 2013

Revised: 27 June 2013 - Accepted: 17 July 2013 - Published: 21 August 2013

\begin{abstract}
Over history, humankind has tended to settle near streams because of the role of rivers as transportation corridors and the fertility of riparian areas. However, human settlements in floodplains have been threatened by the risk of flooding. Possible responses have been to resettle away and/or modify the river system by building flood control structures. This has led to a complex web of interactions and feedback mechanisms between hydrological and social processes in settled floodplains. This paper is an attempt to conceptualise these interplays for hypothetical human-flood systems. We develop a simple, dynamic model to represent the interactions and feedback loops between hydrological and social processes. The model is then used to explore the dynamics of the human-flood system and the effect of changing individual characteristics, including external forcing such as technological development. The results show that the conceptual model is able to reproduce reciprocal effects between floods and people as well as the emergence of typical patterns. For instance, when levees are built or raised to protect floodplain areas, their presence not only reduces the frequency of flooding, but also exacerbates high water levels. Then, because of this exacerbation, higher flood protection levels are required by society. As a result, more and more flooding events are avoided, but rare and catastrophic events take place.
\end{abstract}

\section{Introduction}

Floodplains can be defined as the areas that are periodically inundated by the lateral overflow of rivers (Junk et al., 1989). They are landscape features that are clearly distinguished from neighbouring uplands in terms of their hydrologic processes (Nardi et al., 2006) and among the most valuable ecosystems for providing goods and services to the environment and supporting biodiversity (Opperman et al., 2009). Since the earliest recorded civilisations (e.g. Mesopotamia, Egypt), people have settled in floodplains because they offer favourable conditions for trade, agriculture, and economic development (Di Baldassarre et al., 2010). It is estimated that almost one billion people currently live in floodplains.

There is a very long tradition of studies investigating how humans adjust to floods (White, 1945) and how the occurrence of flooding (i.e. inundation of floodplains) shapes patterns of human settlements and land use (Myers et al., 2008; Green et al., 2011; Schultz and Elliott, 2012). Recent studies have also examined the impact of human interventions (such as flood control measures, land-use change, and urbanisation) on the frequency and magnitude of flooding (Di Baldassarre et al., 2009; Heine and Pinter, 2012; Remo et al., 2012).

However, all these works have been looking at one (or the other) side of the interplay between floods and societies. In hydrology, for example, humans are typically considered as a boundary condition or external forcing to the floodplain systems and reciprocal links are therefore not represented. Hence, there is still a need to understand how societies influence the frequency of flooding, while the frequency of flooding (simultaneously) shapes the development of societies, which (in turn) alter potential floodplain dynamics and feedbacks (Di Baldassarre et al., 2013).

For instance, many societies build and/or raise levees to protect floodplain areas and therefore reduce the frequency of flooding. Then, because of the reduced frequency of flooding, people feel safer and more intense economic development takes place close to the river. This is the so-called "levee 
effect" (White, 1945), whereby, paradoxically, flood control structures might even increase flood risk as protection from frequent flooding reduces perceptions of risk. This encourages human settlements in floodplain areas, which are then vulnerable to high-consequence and low-probability events (Burton and Cutter, 2008; Di Baldassarre et al., 2009; Ludy and Kondolf, 2012). Thus, the process of building and raising levees often leads to a shift from frequent flooding of rural areas to rare, but potentially catastrophic, flooding of urbanised or industrialised areas (e.g. New Orleans, Werner and McNamara, 2007). In some regions of the world, such as California and the Netherlands, a few efforts have been recently made to partly reverse this common trend of continuously reducing the probability of flooding while increasing its potential adverse consequences. In particular, floodplain reconnections were introduced by removing (or lowering) levees or dikes in a number of river reaches (Vis et al., 2003; Opperman et al., 2009; Salazar et al., 2012). It is worth noting that these few attempts to give back some "room for the river" were typically facilitated by the increased environmental consciousness in addition to the growing recognition of floodplains and deltas as precious ecosystems supporting biodiversity (Vis et al., 2003; Opperman et al., 2009; Salazar et al., 2012).

Despite the lack of understanding of these dynamic interactions between floods and societies and the associated feedback mechanisms, the topic remains largely unexplored. In this context, Sivapalan et al. (2012) proposed the new science of socio-hydrology, which researches the two-way coupling of human and water systems. Socio-hydrology will also have a crucial role in Panta Rhei, the upcoming scientific decade of the International Association of Hydrological Sciences (IAHS, Montanari et al., 2013).

In the spirit of socio-hydrology, this paper proposes a conceptualisation of the dynamics of settled floodplains as deeply intertwined human-flood systems to investigate how humans change the frequency and magnitude of flooding, while the frequency and magnitude of flooding in turn shape patterns of human settlements.

We conceptualise the socio-hydrology of floodplains by considering a community that starts settling and developing in a flood-prone area. The human settlement is assumed to develop close to the river and gain the associated economic benefits (e.g. trading). However, the abrupt occurrence of flooding causes economic damages. When the human settlement experiences flood events, the community is shocked and builds awareness of the risk of flooding. Then, people move away from the river (Fig. 1a), build or raise levees to protect the floodplain (Fig. 1b) or respond by a combination of both. If the human settlement moves away from the river, the economic benefits from being in a floodplain decline. Building levees also has an economic cost for the community, and (at the same time) it feeds back on the hydrological system: the presence of levees often exacerbates high water levels, as it may reduce the attenuation of floods and/or
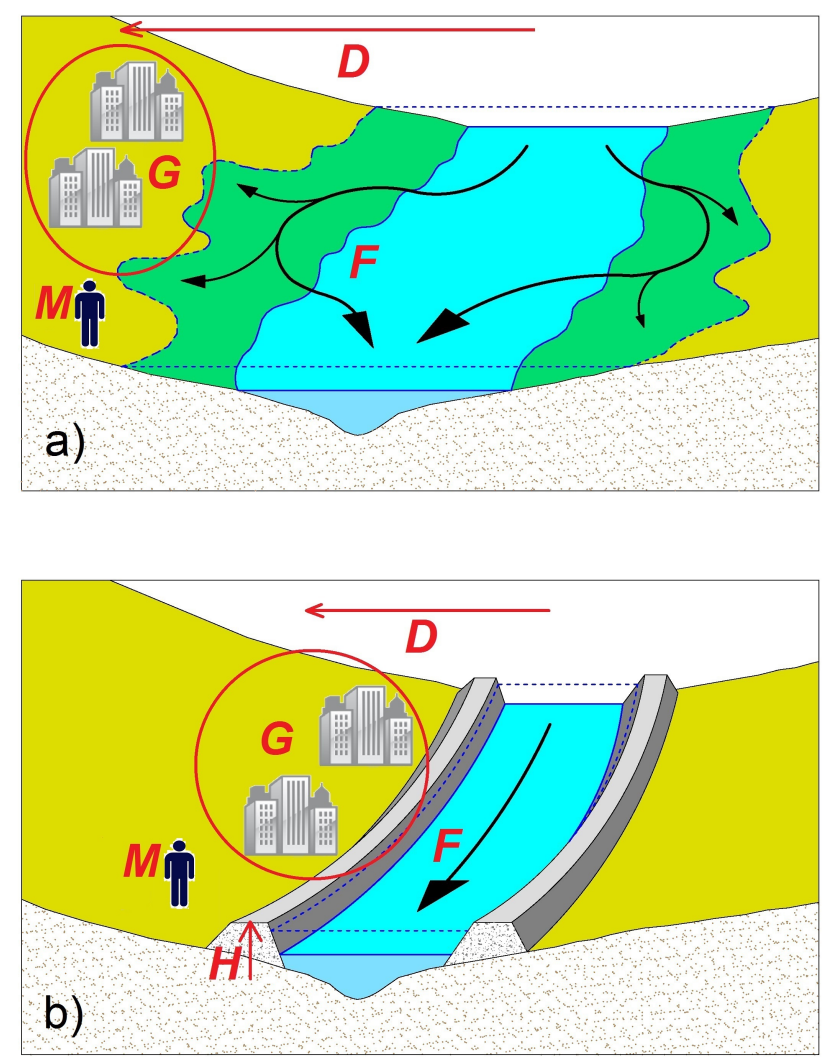

Fig. 1. Schematic of human adjustments to flooding: (a) settling away from the river, and (b) raising levees or dikes. The diagrams also show variables used in our conceptualisation: $F$ is the intensity of flooding [.]; $G$ is the size of human settlement $\left[\mathrm{L}^{2}\right] ; D$ is the distance from the river [L]; $H$ is the flood protection levels [L]; $M$ is the awareness of the risk of flooding [.]. (Based on a sketch by Domenico Di Baldassarre.)

decrease the conveyance of the cross sections (Di Baldassarre et al., 2009; Remo et al., 2012; Heine and Pinter, 2012). Lastly, depending on the memory of the community, the awareness of flood risk decays with time, and, therefore, the tendency to get close to the river and gain economic benefits resumes.

Hence, our conceptualisation considers five different types of processes: hydrological, economical, political, technologi$\mathrm{cal}$, and social (Sect. 2). These components are all interlinked and gradually co-evolve over time, while being abruptly altered by the sudden occurrence of flooding events. It should be noted that we focus on the interactions and feedback mechanisms between these components (Fig. 3). Thus, each component is described by a simple equation, which is meant to capture the most significant processes. 


\section{Conceptualisation}

We conceptualise the dynamics of human-flood systems in a simplified way, through a set of differential equations whose variables are perturbed occasionally by flooding events. We call $W(t)[\mathrm{L}]$ the peak-over threshold time series of water levels above the bankfull depth (hereafter high water levels), which is a sequence of impulses with non-regular time arrivals that may or may not cause flooding. The intensity of flooding events is represented by the variable $F(t)$ [.], which ranges between 0 (no damages) and 1 (total destruction) and is the proportion of damage (or relative damage, e.g. Merz et al., 2011) to the human settlement caused by high values of $W(t)$. We model $F(t)$ with what we call the Hydrology equation:

$F= \begin{cases}1-\exp \left(-\frac{W+\xi_{\mathrm{H}} H_{-}}{\alpha_{\mathrm{H}} D}\right) & \text { if } W+\xi_{\mathrm{H}} H_{-}>H_{-} \\ 0 & \text { otherwise, }\end{cases}$

where the variables evolving with time $t$ are in capital letters (for brevity, the time has not been indicated in the equations) and the parameters are in Greek with subscript $\mathrm{H}=$ Hydrology.

The three variables involved in Eq. (1) are the high water level $W(t)$, the level of the levees $H(t)[\mathrm{L}]$, which can be seen as a measure of flood protection level, and $D(t)[\mathrm{L}]$, which is the distance of the centre of mass of the settlement to the river (Fig. 1). The actual high water level during an event is indicated by $W+\xi_{\mathrm{H}} H_{-}$, where the parameter $\xi_{\mathrm{H}}$ [.] represents the proportion of additional high water levels due to the heightening of levees and $H_{-}$(with the "minus" subscript) is the height of levees immediately before the flooding event. As mentioned, this exacerbation is often caused by reduced flood attenuation and/or altered flood conveyance associated to the presence of levees (Di Baldassarre et al., 2009; Remo et al., 2012; Heine and Pinter, 2012). In particular, Di Baldassarre et al. (2009) used flood inundation modelling to demonstrate that the enhancement of the high water levels in the Po River (Italy) was mainly associated to the building and heightening of the levee system, which was previously hypothesised by Marchi et al. (1996). More recently, Heine and Pinter (2012) further explored the levee effects upon flood levels by analysing the hydrological data of 203 river gauges in Illinois and Iowa. This empirical study showed that high water levels are considerably increased by the presence of levees. This exacerbation of flood levels was found to be "abrupt, statistically significant, and generally large in magnitude" (Heine and Pinter, 2012). Figure 2 shows an example of the interlink between levee heightening and enhancement of high water levels with reference to a real world case study (Adige River at Masi, Italy; Da Deppo et al., 2004).

The parameter $\alpha_{\mathrm{H}}$ [.] is related to the topographic characteristics of the floodplain, i.e. if $\alpha_{\mathrm{H}}$ is high for a given water level the damage reduces considerably with distance, while

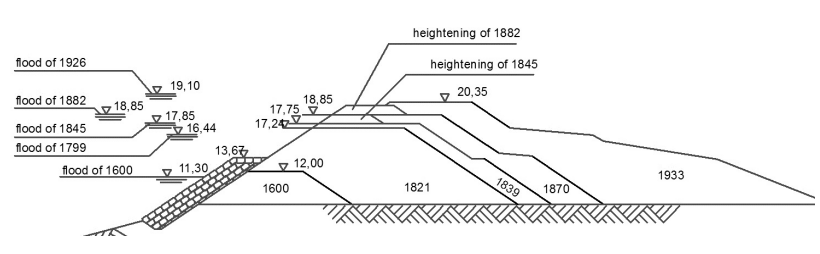

Fig. 2. Historical evolution of the high water levels (left) and levees (right) in the Adige River at Masi (Italy) between 1600 and 1933 (after Da Deppo et al., 2004).

if $\alpha_{\mathrm{H}}=0$ the proportion of damage is the maximum possible (i.e. total destruction, $F=1$ ) irrespective of the water level and the distance of the settlement from the river. For $\alpha_{\mathrm{H}} \neq 0$, total destruction of the settlement is approached when the water level is extremely high and/or the distance from the river approaches 0 . When flooding occurs, i.e. $W+\xi_{\mathrm{H}} H_{-}>$ $H_{-}$, the minimum of $F$ is always positive and approaches 0 for low (flooding) water levels and high distances from the river.

We assume that, immediately after the occurrence of flooding, two decisions may be taken: (i) to raise the levees to a level dependent on the high water level associated to the flooding just experienced, or (ii) not to raise the levees (and possibly move away). The decision to raise the levees is triggered by the incentive and the ability to do so. Given a settlement of size/wealth $G\left[\mathrm{~L}^{2}\right]$, we call $R(t)[\mathrm{L}]$ the amount by which the levees are raised after the flooding event at time $t$ has occurred and we model it as

$R= \begin{cases}\varepsilon_{\mathrm{T}}\left(W+\xi_{\mathrm{H}} H_{-}-H_{-}\right) & \text {if }(F>0) \\ & \text { and }\left(F G_{-}>\gamma_{\mathrm{E}} R \sqrt{G_{-}}\right) \\ & \text {and }\left(G_{-}-F G_{-}>\gamma_{\mathrm{E}} R \sqrt{G_{-}}\right) \\ 0 & \text { otherwise, }\end{cases}$

where $H_{-}$and $G_{-}$are the height of levees and the settlement size immediately before the flooding event. People (or decision-makers) have an incentive to raise the levees if the damage caused by the flooding (i.e. $F G_{-}$) is greater than the cost of building or raising the levees (i.e. $\gamma_{\mathrm{E}} R \sqrt{G_{-}}$, see Eq. $4 \mathrm{a}$ for discussion of these terms). In addition, levees can be raised only if the community is able to afford it: if the costs (i.e. $\gamma_{\mathrm{E}} R \sqrt{G_{-}}$) are lower than the wealth remaining after flooding (i.e. $G_{-}-F G_{-}$). If risen, typically the levees are brought to a level equal or greater to the water level of the last experienced flooding event (Werner and McNamara, 2007) by setting the safety factor $\varepsilon_{\mathrm{T}}[$.$] greater than 1$. Alternatively, other choices can be reproduced by setting the parameter $\varepsilon_{\mathrm{T}}$ smaller than 1 .

In our conceptualisation, the magnitude of the psychological shock experienced by the community immediately after the flooding depends on both the magnitude $F$ of the event and the decision on whether to raise levees and therefore increase the protection level. We define the shock magnitude $S(t)[$.$] with$ 


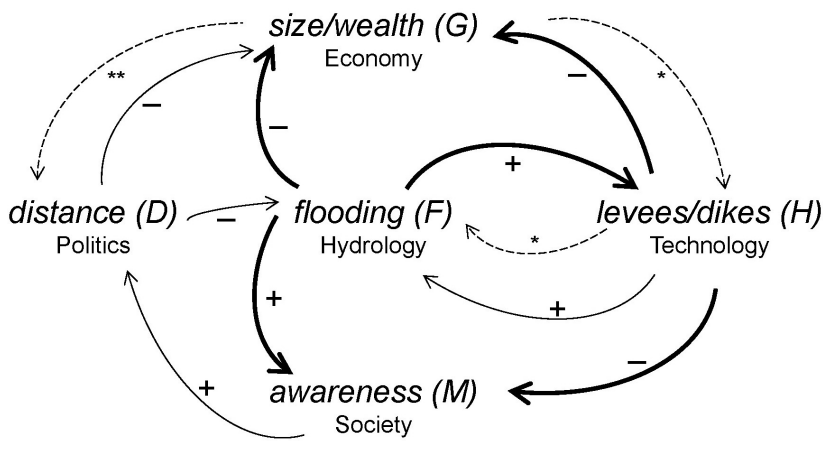

Fig. 3. Loop diagram showing how hydrological, economical, political, technological, and social processes are all interlinked and gradually (continuous thin arrows) co-evolve, while being abruptly (continuous thick arrows) altered by the sudden occurrence of flooding events. Dashed arrows indicate control mechanisms: * conditions in Eqs. (1) and (2); ${ }^{* *}$ ability to move in Eq. (4b).

$S= \begin{cases}\alpha_{\mathrm{S}} F & \text { if }(R>0) \\ F & \text { otherwise }\end{cases}$

which goes from 0 to 1 similarly to the proportion of damage $F$ produced by the flooding event. If no additional protection measures are built after the event (i.e. $R=0$ ), the shock is equal to $F$. If protection measures are built, i.e. levees are raised to a level $R$, the shock may be less than $F$ and the sense of security created corresponds to $1-\alpha_{\mathrm{S}}$. If the parameter $\alpha_{\mathrm{S}}$ [.] is 0 , it is assumed that people perceive the building of additional protection levels as a total remedy and they feel completely safe from future events (Ludy and Kondolf, 2012). Hence $\alpha_{\mathrm{S}}>0$ means that the remedy is not enough to completely alleviate the shock due to the flooding. In the limiting case, i.e. $\alpha_{\mathrm{S}}=1$, the community keeps its awareness at the maximum level notwithstanding the construction of additional protection levels.

Equations (1)-(3) describe the mechanisms happening during flooding events, i.e. in our conceptual model we lump, as single events, flooding, psychological shock, and the decision to take action by raising the protection level. In the following we describe the dynamic system, which is fully coupled to the Hydrology Eq. (1). The system consists of four differential equations:

$$
\left\{\begin{aligned}
\frac{\mathrm{d} G}{\mathrm{~d} t} & =\rho_{\mathrm{E}}\left(1-\frac{D}{\lambda_{\mathrm{E}}}\right) G+ & & \\
& -\Delta(\Upsilon(t)) \cdot\left(F G+\gamma_{\mathrm{E}} R \sqrt{G}\right) & & \text { Economy } \\
\frac{\mathrm{d} D}{\mathrm{~d} t} & =\left(M-\frac{D}{\lambda_{\mathrm{P}}}\right) \frac{\varphi_{\mathrm{P}}}{\sqrt{G}} & & \text { Politics } \\
\frac{\mathrm{d} H}{\mathrm{~d} t} & =\Delta(\Upsilon(t)) R-\kappa_{\mathrm{T}} H & & \text { Technology } \\
\frac{\mathrm{d} M}{\mathrm{~d} t} & =\Delta(\Upsilon(t)) S-\mu_{\mathrm{S}} M & & \text { Society }
\end{aligned}\right.
$$

The system represents how economy, politics, technology and society are altered by the hydrology of flooding, which is in turn influenced by them (see also Appendix A). Thus, our conceptualisation of settled floodplains captures the dynamic two-way coupling of human and water systems (Fig. 3).

The first differential equation is the Economy equation, in which $G(t)\left[\mathrm{L}^{2}\right]$ is the size of the human settlement at time $t$, which is also related to number of people, physical size, and economic wealth. Equation (4a) states that the change in $G$ with time is driven by two main components: a gradual growing/shrinking component, which is proportional to $G$ itself, and an abrupt shrinking component which is due to flood damage. The parameter $\rho_{\mathrm{E}}\left[\mathrm{T}^{-1}\right]$ is the maximum relative growth rate of the human settlement when the benefits from being close to the river are maximised. $\rho_{\mathrm{E}}$ is therefore extrinsically driven and linked to the (regional or global) economy. We assume that economic benefits derive from settling as close as possible to the river and we model the penalty of settling away from it with the term $1-D / \lambda_{\mathrm{E}}$. With the parameter $\lambda_{\mathrm{E}}[\mathrm{L}]$ we indicate a critical distance from the river beyond which the settlement can no longer grow. Therefore the growth rate is linearly related to the distance $D$ and, if the community moves beyond the distance $\lambda_{\mathrm{E}}$, the growth can be negative.

The abrupt shrinking of $G$ due to the flood damage is modelled as instantaneous through a non periodic Dirac comb $\Delta$ $\left[\mathrm{T}^{-1}\right]$ that is always 0 except when $\Upsilon(t)=0$, in which case it is $+\infty$ with integral equal to 1 . Since $\Upsilon(t)$ is defined as a function whose roots are located at times $t$ of flooding occurrences, the term $\left(F G+\gamma_{\mathrm{E}} R \sqrt{G}\right)$ exists only for flooding events. The variables $F$ and $R$ have been defined in Eqs. (1) and (2). The term $F G$ in Eq. (4a) is the flooding damage while the term $\gamma_{\mathrm{E}} R \sqrt{G}$ is the cost of building or raising levees. The parameter $\gamma_{E}[$.$] is the cost, in this case described in$ terms of reduction in the settlement's area, for unit hight $R$ and width $\sqrt{G}$ of levee raising (assuming $\sqrt{G}$ as a representative length of the settlement edge to protect). In case of high water levels, i.e. $\Delta(\Upsilon(t))=1$, the wealth of the community shrinks because of damage due to flooding $F$ and because of costs of raising the levees by a quantity $R$.

The variation in time of the distance $D(t)[\mathrm{L}]$ of the center of mass of the human settlement from the river is the second differential equation and is called here the Politics equation (Eq. 4b). The movement towards and away from the river is driven by the incentive to move in that direction and by the ability to move. With $M(t)$ [.] we indicate the awareness to flood risk based on experience/memory of prior events at time $t$ (see Eq. 4d). High $M$ leads people (or decision-makers) to settle away from the river, i.e. the settlement grows at higher distances from the river, thus increasing the distance of its centre of mass $D$. However societies can tolerate flooding because of the economic benefits of being close to the river. This is modelled in Eq. (4b) by the term $-D / \lambda_{\mathrm{P}}$. The parameter $\lambda_{\mathrm{P}}[\mathrm{L}]$ represents the trade off between the memory of flooding events (which makes the community move away from the river) versus the willingness to maximise economic benefit by moving close to the river. Note that $\lambda_{\mathrm{P}}$ is related to perception of risk (see e.g. 
Wachinger et al., 2012) and political behaviour. Communities and decision-makers may select the tolerance level based on economic reasoning (Schumann and Nijssen, 2011), their personal attitude or group culture of being risk-taking or risk-adverse. Political processes, e.g. popular opinion and approaching elections, are likely to further drive decisions.

The last term in Eq. (4b) defines the ability to move the center of mass of the settlement. We assume that larger urban areas (i.e. more wealthy settlements) are less capable of moving because resettling large groups of people is more challenging than resettling small groups. The term $\varphi_{\mathrm{P}} / \sqrt{G}$ $\left[\mathrm{LT}^{-1}\right]$ can be seen as the inertia assumed inversely proportional to the representative length $\sqrt{G}$ of the human settlement. The parameter $\varphi_{\mathrm{P}}\left[\mathrm{L}^{2} \mathrm{~T}^{-1}\right]$ can be therefore seen as a flux parameter and defines the rate by which new properties can be built.

The variation in time of the protection level $H(t)[\mathrm{L}]$ is the third differential equation and is called here the Technology equation (Eq. 4c). The construction of flood protection is driven by the incentive and ability to raise levees as defined in Eq. (2). It is assumed that immediately after a flooding event, awareness to flood risk is high and, where feasible, levees are immediately constructed. The second term in Eq. (4c) represents the decay of the structural measures with time and the parameter $\kappa_{\mathrm{T}}\left[\mathrm{T}^{-1}\right]$ is the rate of that decay, which depends on the technology used. Given the focus on the interplay between the processes within a floodplain system, equations are parsimonious and describe the five different types of processes with the same level of (reduced) complexity. Additional terms can be added to account for additional aspects, when considered significant. For instance, one more parameter can be added to the Economy equation to simulate a logistic rather than an exponential growth, or an additional term can be added to Technology equation to account for augmentation and/or repair of flood protection structures.

The variation in time of awareness of flood risk $M(t)$ [.] is the fourth differential equation and is called here the Social equation (Eq. 4d). It expresses the accumulation of awareness because of psychological shocks $S$ experienced by people during events (see Eq. 3) and its decay due to forgetting these experiences $\mu_{\mathrm{S}} M$, where the parameter $\mu_{\mathrm{S}}\left[\mathrm{T}^{-1}\right]$ represents the memory loss rate. The assumption of building risk awareness only immediately after the occurrence of flood events was derived by the findings of Baan and Klijn (2004), Parker et al. (2011), and Scolobig et al. (2012). More specifically, Scolobig et al. (2012) interviewed 400 people living in flood-prone areas and found out that previous experience of flooding was indicated by $90 \%$ of the respondents as the main drive for risk awareness, whereas only a small minority ( $5 \%)$ mentioned "official information" as one of the motives for risk awareness. The decay of risk awareness is schematised to reflect the experience that the high risk awareness that is commonly observed during and immediately after flooding tends to rapidly dissipate afterwards (Baan and Klijn, 2004).

\section{Results}

To illustrate the dynamics of the conceptualised flood-human interactions, we show a number of simulations for an hypothetical community, named WetTown, settling in the floodplain of the WildWaters River. We assume that at time $t=0$, WetTown is a small village of $10000 \mathrm{~m}^{2}(G(t=0))$, situated at $2000 \mathrm{~m}$ from the river $(D(t=0))$. Having just settled in this area, people do not have experience of flooding $(M(t=0)=0)$ and there are no structural measures (e.g. levees) for flood protection $(H(t=0)=0 \mathrm{~m})$.

The community starts to get wealthier and therefore larger by trading, facilitated by being settled close to the WildWaters River. The river acts as an efficient transportation corridor and allows a maximum growth-rate of $2 \%\left(\rho_{\mathrm{E}}\right)$, which declines when the distance from the river increases and vanishes at $5000 \mathrm{~m}\left(\lambda_{\mathrm{E}}\right)$.

At the same time, high water levels $(W(t))$ may potentially inundate WetTown $\left(\alpha_{\mathrm{H}}=0.01\right)$ and compromise its economic development. In case of flooding, the inhabitants of WetTown experience a shock that is halved if levees are raised $\left(\alpha_{S}=0.5\right)$. The shock contributes to the accumulation of awareness, which decays by $50 \%$ in about $15 \mathrm{yr}$ $\left(\mu_{\mathrm{S}}=0.05 \mathrm{yr}^{-1}\right)$.

The memory of flooding makes the community willing to move away from the river. The distance that is perceived as completely safe is $12000 \mathrm{~m}\left(\lambda_{\mathrm{P}}\right)$ and the ability to resettle is proportional to $\varphi_{P}=100^{2} \mathrm{~m}^{2} \mathrm{yr}^{-1}$.

Figure 4a shows a hypothetical time series of high water levels $(W(t))$ of the WildWaters River for $2000 \mathrm{yr}$. To explore the evolution of WetTown, we use our conceptual model to simulate the dynamic interactions and feedback mechanisms between the development of the village and the hydrology of floods. We consider three scenarios characterised by different costs of building/raising levees: low-cost $\left(\gamma_{\mathrm{E}}=0.5\right)$, moderate-cost $\left(\gamma_{\mathrm{E}}=50\right)$ and high-cost $\left(\gamma_{\mathrm{E}}=5000\right)$. In all these scenarios, we assume that the decay of protection levels is of about $50 \%$ in $200 \mathrm{yr}$ (i.e. $\kappa_{\mathrm{T}}=3 \times 10^{-3} \mathrm{yr}^{-1}$ ) and that levees determine a $50 \%$ exacerbation $\left(\xi_{\mathrm{H}}=0.5\right)$ of the high water levels.

Panels b-f of Fig. 4 show the results of the simulations for the three scenarios: low-cost in red, moderate-cost in blue and high-cost in green. Figure $4 b$, in particular, shows the effect of different unit costs of flood protection structures: in the low-cost scenario levees are built immediately after the first flooding has occurred; in the high-cost scenario the community never reaches the wealth necessary to afford the expenses of building levees; while in the moderate-cost scenario a shift happens at circa year 700 when the levees are first built.

By analysing Fig. 4c, one can observe that the tendency of the community to move close to the river is exaggerated when levees are built (e.g. Fig. 1). Being close to the river enhances the economic growth of WetTown, but also its vulnerability to flooding. In fact, Fig. $4 d$ shows that in 

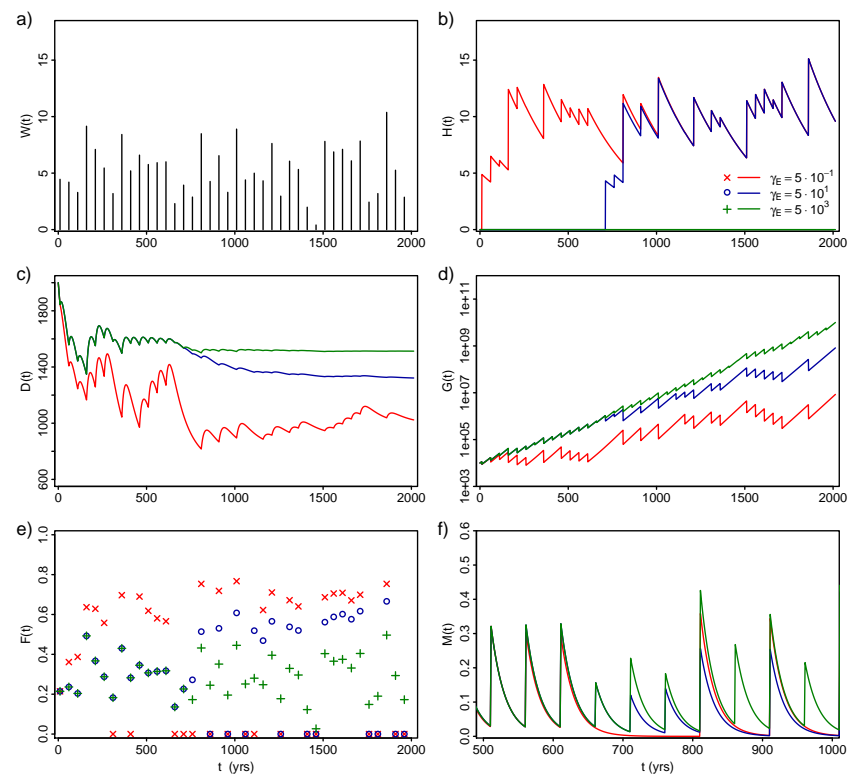

Fig. 4. The evolution of WetTown assuming a fast decay of protection levels (i.e. $\kappa_{\mathrm{T}}=3 \times 10^{-3} \mathrm{yr}^{-1}$ ): (a) high water levels [m]; (b) flood protection levels [m]; (c) distance of WetTown from WildWaters River $[\mathrm{m}]$; (d) size/wealth of WetTown $\left[\mathrm{m}^{2}\right]$; (e) relative flood damages [.]; (f) awareness of the risk of flooding [.]. The colour of lines and points refers to the three scenarios: low-cost (red), moderate-cost (blue) and high-cost (green).

the low-cost scenario the fast growth is jeopardised by the severity of flood damages, while in the high-cost scenarios growth is less impacted by the occurrence of flooding. So, in the high-cost scenario, the higher growth rate experienced by WetTown results in a decreased ability to move (Fig. 4c) and the establishment of WetTown at a relative stable distance after about $1000 \mathrm{yr}$. At this distance, a balance is found between economic growth and flood damages. On the other hand, in the low-cost scenario WetTown does not grow fast and continuously resettles back and forth from the river triggered by flooding events. It is interesting to note the dynamics of the moderate-cost scenario. Until circa year 700, when levees are first built, the behaviour is exactly the same as in the highcost scenario (Fig. 4b-d), because the community does not have resources to start building levees. As soon as it starts to build levees, the settlement gets closer to the river (Fig. 4c) and this affects its long term economic growth (Fig. 4d).

Figure $4 \mathrm{e}$ shows the intensity of flooding in terms of relative damage for the three scenarios. The most striking result is the avoidance of frequent, small flooding events at the cost of rare, but catastrophic events when levees are in place (red crosses). On the contrary, when levees are not built (green pluses), every high-water event produces flooding but the relative damage is less. There are two reasons for this, which show up clearly by looking at the dynamics of the moderate-cost scenario (blue circles). Until year 700 flooding events are as frequent and of moderate intensity as in the
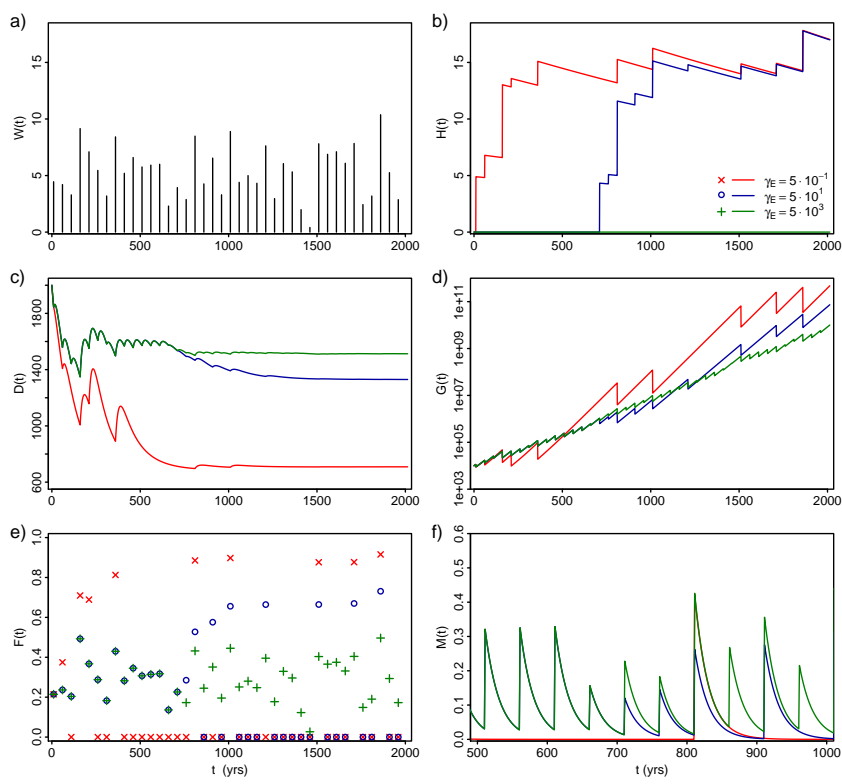

Fig. 5. The evolution of WetTown assuming a slow decay of protection levels (i.e. $\kappa_{\mathrm{T}}=3 \times 10^{-4} \mathrm{yr}^{-1}$ ): (a) high water levels [m]; (b) flood protection levels [m]; (c) distance of WetTown from WildWaters River $[\mathrm{m}]$; (d) size/wealth of WetTown $\left[\mathrm{m}^{2}\right]$; (e) relative flood damages [.]; (f) awareness of the risk of flooding [.]. The colour of lines and points refers to the three scenarios: low-cost (red), moderate-cost (blue) and high-cost (green).

high-cost scenario. Afterwards, because of the presence of levees, some events are avoided, while others enhanced. The enhancement is due to: (i) WetTown resettling closer to the river, and (ii) high water levels exacerbated by the presence of levees. The exacerbation of high water levels (in turn) also causes differences in the dynamics of the protection levels (Fig. 4b), which is visible by comparing the moderate- and high-cost scenarios between years 700 and 1000. In this period, in the moderate-scenario the community starts building levees, which are lower than in the low-cost scenarios because the exacerbation of high water levels has not yet taken place.

By looking at peoples' awareness of risk in the transition period around year 700 (Fig. 4f), one notices that the presence of levees reduces the awareness of flooding because of two reasons: (i) the reduction in the frequency of flooding; and (ii) the false sense of security due to the construction of additional protection levels. This reduced awareness of flooding in turn determines the tendency to move closer to the river and therefore being strongly affected by floods.

As an additional illustration, Fig. 5 depicts a different assumption on the decay of the flood protection levels, which is of about $5 \%$ in $200 \mathrm{yr}$ (i.e. $\kappa_{\mathrm{T}}=3 \times 10^{-4} \mathrm{yr}^{-1}$, much lower than in Fig. 4). The different decay can be seen by comparing Fig. $5 \mathrm{~b}$ to Fig. $4 \mathrm{~b}$ and it may correspond to a better technology used for the construction of the levees. The impact of the lower decay of the flood protection structures is twofold: the 
low-cost scenario has the strongest overall growth (Fig. 5d) while it had the weakest one in Fig. 4d; and in the low-cost scenario only very few high water levels result in flooding, but of higher intensity (Fig. 5e). This higher impact of rare but catastrophic flooding events is linked to the low awareness of risk (Fig. 5f) and the close location of the settlement to the river (Fig. 5c).

These example applications focused on the parameters of the Technology equation to show the impact of flood protection measures on the long-term dynamics of floodplain systems. Future research work will also explore the sensitivity of the conceptual model to different parameters as well as the changes in the evolution pattern induced by altered parameters (e.g. Lin et al., 2013).

The resulting long-term dynamics produced by the sociohydrological model (Figs. 4 and 5) were found to reproduce the typical patterns observed in many deltas and floodplain systems around the world. One of the most striking elements is that when flood protection structures (e.g. levees) are economically affordable, a shift from frequent flooding to rare (but disastrous) flooding occurs. Werner and McNamara (2007) showed the emergence of this behaviour for the case study of New Orleans, while Di Baldassarre et al. (2013) highlighted this tendency in the Po River basin. For instance, Fig. 6 shows, as an example of these dynamics, the Po River at Occhiobello (Italy), whereby continuous levee heightening has contributed to the increased human population in the floodplain area (the aforementioned "levee effect"), and vice versa. Interestingly, such a population growth was first interrupted during the Second World War and later, much more drastically, by the occurrence of the 1951 flooding, which was caused by levee failure. After the 1951 flooding, higher levees were built and population growth resumed (Fig. 6).

\section{Conclusions}

This paper describes the conceptualisation of sociohydrological processes in settled floodplains. The high complexity of hydrological, economical, political, technological, and social processes is simplified as much as possible. This is consistent with our goal to focus on the interactions and feedbacks between these different components.

Our conceptualisation simulates dominant dynamics in floodplains as fully coupled human-flood systems. It allows, for instance, a comparison of different trajectories of economic development corresponding to scenarios where people deal with flooding by moving away from the river (e.g. living with floods) versus scenarios where people build levees to protect floodplain areas (e.g. fighting floods). It also shows the emergence of typical patterns experienced in many societies, such as the shift from the occurrence of frequent, small flooding events to the occurrence of rare, catastrophic flood disasters (Werner and McNamara, 2007).

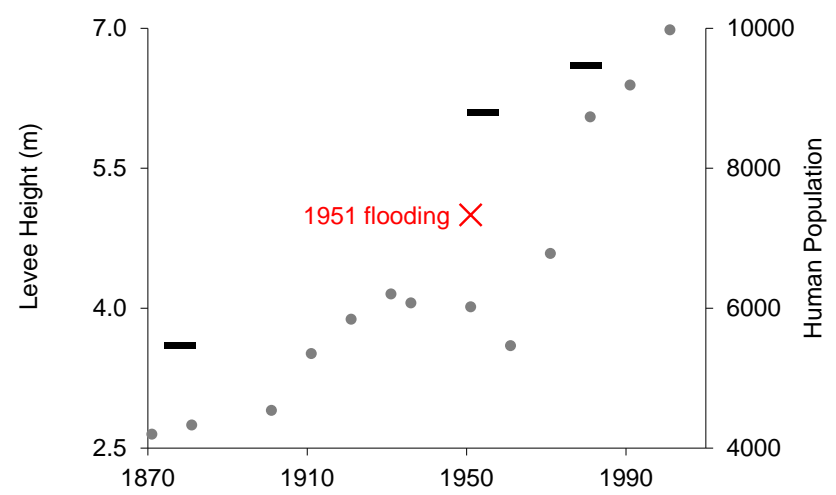

Fig. 6. Example of long-term dynamics of human-flood interactions: human population in Occhiobello (grey dots), surveyed height of the levee system (black rectangular dots), and high water level during the 1951 flooding (red cross).

It should be noted, however, that this conceptualisation unavoidably neglects some potentially significant aspects related to the heterogeneity of human societies (Di Baldassarre et al., 2013), such as the fact that some population groups have less resources than others to move or choose not to move because they have more to gain by being close to the river and are willing to take more risk. Likewise, this lumped model neglects the heterogeneity of hydrological, economical, technological, and political processes. Also, given the focus on the interactions and feedbacks between these different processes, they are all schematised by simple and parsimonious equations, characterised by the same level of reduced complexity.

Thus, this conceptualisation should be considered as an educated hypothesis of how human-flood systems work in a generalised way, rather than as a predictive tool for a particular location. This conceptualisation enables the unravelling of feedbacks between hydrological and social processes.

We aim to test the validity of our assumptions by further exploring the socio-hydrology of floodplain systems, also via comparative analysis of long time series of social and hydrological data, along with information about the human interactions with the environment (e.g. urbanisation, land use, flood control structures) for diverse case studies, across scales (Blöschl, 2006), levels of human impact and different cultures.

\section{Appendix A}

\section{List of symbols}

Tables A1 and A2 list the variables and parameters of the dynamic system, and their initial conditions and values in the examples of Sect. 3. The subscripts of parameters refer to the specific domain $(\mathrm{E}=$ Economy, $\mathrm{P}=$ Politics, $\mathrm{T}=$ Technology, $\mathrm{S}=$ Society). 
Table A1. Variables of the dynamic system and their initial conditions in the examples of Sect. 3 (Figs. 4 and 5).

\begin{tabular}{lllllll}
\hline & Units & Description & Eq. & Domain & Type & Initial conditions \\
\hline$F$ & {$[]$.} & intensity of flooding & $(1)$ & Hydrology & event & 0 \\
$G$ & {$\left[\mathrm{~L}^{2}\right]$} & $\begin{array}{l}\text { size of the human settlement as a } \\
\text { measure of wealth }\end{array}$ & $(4 \mathrm{a})$ & Economy & state & $100^{2} \mathrm{~m}^{2}$ \\
& & & & & \\
$D$ & {$[\mathrm{~L}]$} & distance from the river & $(4 \mathrm{~b})$ & Politics & state & $2000 \mathrm{~m}$ \\
$R$ & {$[\mathrm{~L}]$} & amount by which the levees are raised & $(2)$ & Technology & event & $0 \mathrm{~m}$ \\
& & after flooding & $(4 \mathrm{c})$ & Technology & state & $0 \mathrm{~m}$ \\
$H$ & {$[\mathrm{~L}]$} & flood protection levels & $(3)$ & Society & event & 0 \\
$S$ & {$[]$.} & shock magnitude & $(4 \mathrm{~d})$ & Society & state & 0 \\
$M$ & {$[]$.} & awareness of flood risk & & & &
\end{tabular}

Table A2. Parameters of the dynamic system and their values in the examples of Sect. 3 (Figs. 4 and 5).

\begin{tabular}{|c|c|c|c|c|c|}
\hline & Units & Description & Eq. & Domain & Values \\
\hline$\xi_{\mathrm{H}}$ & [.] & $\begin{array}{l}\text { proportion of additional high water level due to } \\
\text { levee heightening }\end{array}$ & (1) & Hydrology & 0.5 \\
\hline$\alpha_{\mathrm{H}}$ & [.] & $\begin{array}{l}\text { parameter related to the slope of the floodplain } \\
\text { and the resilience of the human settlement }\end{array}$ & $(1)$ & Hydrology & 0.01 \\
\hline$\rho_{\mathrm{E}}$ & {$\left[\mathrm{T}^{-1}\right]$} & maximum relative growth rate & $(4 a)$ & Economy & $0.02 \mathrm{yr}^{-1}$ \\
\hline$\lambda_{\mathrm{E}}$ & {$[\mathrm{L}]$} & $\begin{array}{l}\text { critical distance from the river beyond which } \\
\text { the settlement can no longer grow }\end{array}$ & $(4 a)$ & Economy & $5000 \mathrm{~m}$ \\
\hline$\gamma_{\mathrm{E}}$ & [.] & $\begin{array}{l}\text { cost for unit hight } R \text { and width } \sqrt{G} \text { of levee } \\
\text { raising }\end{array}$ & $(4 a)$ & Economy & $5 \times 10^{-1}, 5 \times 10^{1}, 5 \times 10^{3}$ \\
\hline$\lambda_{\mathrm{P}}$ & {$[\mathrm{L}]$} & $\begin{array}{l}\text { distance at which people would accept to live } \\
\text { when they remember past floods whose total } \\
\text { consequences were perceived as a total } \\
\text { destruction of the settlement }\end{array}$ & $(4 b)$ & Politics & $12000 \mathrm{~m}$ \\
\hline$\varphi_{\mathrm{P}}$ & {$\left[\mathrm{L}^{2} \mathrm{~T}^{-1}\right]$} & rate by which new properties can be built & $(4 b)$ & Politics & $100^{2} \mathrm{~m}^{2} \mathrm{yrs}^{-1}$ \\
\hline$\varepsilon_{\mathrm{T}}$ & {$[]$.} & safety factor for levees rising & $(2)$ & Technology & 1.1 \\
\hline$\kappa_{\mathrm{T}}$ & {$\left[\mathrm{T}^{-1}\right]$} & rate of that decay of levees & $(4 c)$ & Technology & $3 \times 10^{-3} \mathrm{yr}^{-1}, 3 \times 10^{-4} \mathrm{yr}^{-1}$ \\
\hline$\alpha_{\mathrm{S}}$ & {$[]$.} & $\begin{array}{l}\text { proportion of shock after flooding if levees are } \\
\text { risen }\end{array}$ & (3) & Society & 0.5 \\
\hline$\mu_{\mathrm{S}}$ & {$\left[\mathrm{T}^{-1}\right]$} & memory loss rate & $(4 d)$ & Society & $0.05 \mathrm{yr}^{-1}$ \\
\hline
\end{tabular}

Acknowledgements. The authors would like to thank Alexia Furnkranz-Prskawetz and Luigia Brandimarte for providing comments on an earlier draft of this paper. The research of Giuliano Di Baldassarre was partly funded by the KULTURisk project (EC FP7 Grant Agreement no. 265280). Financial support for Doctoral program DK-plus W1219-N22, funded by the Austrian Science Funds, and the FloodChange project, funded by the European Research Council (ERC), are also acknowledged.

Edited by: V. Srinivasan

\section{References}

Baan, P. and Klijn, F.: Flood risk perception and implications for flood risk management in the Netherlands, Int. J. River Basin Manage., 2, 113-122, 2004.

Blöschl, G.: Hydrologic synthesis: across processes, places, and scales, Water Resour. Res., 42, W03S02, doi:10.1029/2005WR004319, 2006.
Burton, C. and Cutter, S. L.: Levee failures and social vulnerability in the Sacramento-San Joaquin Delta area, California, Natural Hazards Review, 9, 136-149, doi:10.1061/(ASCE)15276988(2008)9:3(136), 2008.

Da Deppo, L., Datei, C., and Salandin, P.: Sistemazione dei corsi d'acqua, Libreria Internazionale Cortina Padova, 815 pages, Padova, Italy, ISBN: 88-7784-246-6, 2004 (in Italian).

Di Baldassarre, G., Castellarin, A., and Brath, A.: Analysis on the effects of levee heightening on flood propagation: some thoughts on the River Po, Hydrolog. Sci. J., 54, 1007-1017, doi:10.1623/hysj.54.6.1007, 2009.

Di Baldassarre, G., Montanari, A., Lins, H., Koutsoyiannis, D., Brandimarte, L., and Blöschl, G.: Flood fatalities in Africa: from diagnosis to mitigation, Geophys. Res. Lett., 37, L22402, doi:10.1029/2010GL045467, 2010.

Di Baldassarre, G., Kooy, M., Kemerink, J. S., and Brandimarte, L.: Towards understanding the dynamic behaviour of floodplains as human-water systems, Hydrol. Earth Syst. Sci., 17, 3235-3244, doi:10.5194/hess-17-3235-2013, 2013. 
Green, C., Viavattene, C., and Thompson, P.: Guidance for Assessing Flood Losses, Tech. rep., Flood Hazard Research Centre, Middlesex University, 2011.

Heine, R. and Pinter, N.: Levee effects upon flood levels: an empirical assessment, Hydrol. Process., 26, 3225-3240, doi:10.1002/hyp.8261, 2012.

Junk, W. J., Bayley, P. B., and Sparks, R. E.: The flood pulse concept in river-floodplain systems, in: Proceedings of the International Large River Symposium, Vol. 106, 110-127, 1989.

Lin, M., Tian, F., Hu, H., and Liu, D.: Nonsmooothl dynamic behaviors inherited from an ecohydrological model: mutation, bifurcation and chaos, Math. Probl. Eng., 2013, 731042, doi:10.1155/2013/731042, 2013.

Ludy, J. and Kondolf, G.: Flood risk perception in lands "protected" by 100-year levees, Nat. Hazards, 61, 829-842, doi:10.1007/s11069-011-0072-6, 2012.

Marchi E., Roth, G., and Siccardi, F.: The Po: Centuries of River Training, Phys. Chem. Earth, 20, 475-478, 1996.

Merz, B., Thieken, A. H., and Kreibich, H.: Quantification of Socio-Economic Flood Risk, Chap. 11, Springer, 229-247, doi:10.1007/978-90-481-9917-4_11, 2011.

Montanari, A., Young, G., Savenije, H. H. G., Hughes, D., Wagener, T., Ren, L. L., Koutsoyiannis, D., Cudennec, C., Toth, E., Grimaldi, S., Blöschl, G., Sivapalan, M., Beven, K., Gupta, H., Hipsey, M., Schaefli, B., Arheimer, B., Boegh, E., Schymanski, S. J., Di Baldassarre, G., Yu, B., Hubert, P., Huang, Y., Schumann, A., Post, D. A., Srinivasan, V., Harman, C., Thompson, S., Rogger, M., Viglione, A., McMillan, H., Characklis, G., Pang, Z., and Belyaev, V.: Panta Rhei - Everything Flows: Change in hydrology and society - The IAHS Scientific Decade, 2013-2022, Hydrolog. Sci. J., 58, 1256-1275, doi:10.1080/02626667.2013.809088, 2013.

Myers, C., Slack, T., and Singelmann, J.: Social vulnerability and migration in the wake of disaster: the case of Hurricanes Katrina and Rita, Popul. Environ., 29, 271-291, doi:10.1007/s11111008-0072-y, 2008.

Nardi, F., Vivoni, E. R., and Grimaldi, S.: Investigating a floodplain scaling relation using a hydrogeomorphic delineation method, Water Resour. Res., 42, W09409, doi:10.1029/2005WR004155, 2006.

Opperman, J., Galloway, G., Fargione, J., Mount, J., Richter, B., and Secchi, S.: Sustainable floodplains through largescale reconnection to rivers, Science, 326, 1487-1488, doi:10.1126/science.1178256, 2009.
Parker, D., Priest, S., and McCarthy, S.: Explore surface water flood warning requirements and potential in England and Wales, Appl. Geogr., 31, 891-900, 2011.

Remo, J., Megan, C., and Pinter, N.: Hydraulic and flood-loss modeling of levee, floodplain, and river management strategies, Middle Mississippi River, USA, Nat. Hazards, 61, 551-575, doi:10.1007/s11069-011-9938-x, 2012.

Salazar, S., Francés, F., Komma, J., Blume, T., Francke, T., Bronstert, A., and Blöschl, G.: A comparative analysis of the effectiveness of flood management measures based on the concept of "retaining water in the landscape" in different European hydroclimatic regions, Nat. Hazards Earth Syst. Sci., 12, 3287-3306, doi:10.5194/nhess-12-3287-2012, 2012.

Schultz, J. and Elliott, J.: Natural disasters and local demographic change in the United States, Popul. Environ., 34, 293-312, doi:10.1007/s11111-012-0171-7, 2012.

Schumann, A. H. and Nijssen, D.: Application of Scenarios and Multi-Criteria Decision Making Tools in Flood Polder Planning, chap. 12, Springer, doi:10.1007/978-90-481-9917-4_12, 249275, 2011.

Scolobig, A., De Marchi, B., and Borga, M.: The missing link between flood risk awareness and preparedness: findings from case studies in an Alpine Region, Natural Hazards, 63, 499-520, 2012.

Sivapalan, M., Savenije, H. H., and Blöschl, G.: Socio-hydrology: a new science of people and water, Hydrol. Process., 26, 12701276, doi:10.1002/hyp.8426, 2012.

Vis, M., Klijn, F., De Bruijn, K. M., and Van Buuren, M.: Resilience strategies for flood risk management in the Netherlands, Int. J. River Basin Manage., 1, 33-40, doi:10.1080/15715124.2003.9635190, 2003.

Wachinger, G., Renn, O., Begg, C., and Kuhlicke, C.: The Risk Perception Paradox - implications for governance and communication of natural hazards, Risk Anal., 33, 1049-1065, doi:10.1111/j.1539-6924.2012.01942.x, 2012.

Werner, B. and McNamara, D.: Dynamics of coupled human-landscape systems, Geomorphology, 91, 393-407, doi:10.1016/j.geomorph.2007.04.020, 2007.

White, G. F.: Human Adjustments to Floods, Department of Geography Research, Paper no. 20, 29, The University of Chicago, Chicago, 1945. 